\title{
Production of medically useful bromine isotopes via alpha-particle induced nuclear reactions
}

\author{
Katharina Breunig ${ }^{1}$, Bernhard Scholten ${ }^{1, \text { a }}$, Ingo Spahn ${ }^{1}$, Alex Hermanne ${ }^{2}$, Stefan Spellerberg ${ }^{1}$, Heinz H. Coenen ${ }^{1}$, \\ and Bernd Neumaier ${ }^{1}$ \\ ${ }^{1}$ Forschungszentrum Jülich, Institute of Neuroscience and Medicine, INM-5: Nuclear Chemistry, 52428 Jülich, Germany \\ 2 Vrije Universiteit Brussel (VUB), Cyclotron Laboratory, 1050 Brussels, Belgium
}

\begin{abstract}
The cross sections of $\alpha$-particle induced reactions on arsenic leading to the formation of ${ }^{76,77,78} \mathrm{Br}$ were measured from their respective thresholds up to $37 \mathrm{MeV}$. Thin sediments of elemental arsenic powder were irradiated together with $\mathrm{Al}$ degrader and $\mathrm{Cu}$ monitor foils using the established stacked-foil technique. For determination of the effective $\alpha$-particle energies and of the effective beam current through the stacks the cross-section ratios of the monitor nuclides ${ }^{67} \mathrm{Ga} /{ }^{66} \mathrm{Ga}$ were used. This should help resolve discrepancies in existing literature data. Comparison of the data with the available excitation functions shows some slight energy shifts as well as some differences in curve shapes. The calculated thick target yields indicate, that ${ }^{77} \mathrm{Br}$ can be produced in the energy range $\mathrm{E}_{\alpha}=25 \rightarrow 17 \mathrm{MeV}$ free of isotopic impurities in quantities sufficient for medical application.
\end{abstract}

\section{Introduction}

Halogens have been shown to be useful for labelling molecules for diagnosis and therapy in nuclear medicine. One of the main radionuclides is ${ }^{18} \mathrm{~F}$ with 110 min half-life for Positron Emission Tomography (PET) studies, besides several radioiodine isotopes used in diagnosis and therapy.

Fluorine has the strongest carbon-halogen bond, apart from that use of ${ }^{18} \mathrm{~F}$ is limited to PET and the radionuclide has a too short half-life to study slow metabolic processes, i.e. of proteins and peptides. Iodine on the other side has isotopes with different decay characteristics suitable for a broader spectrum of medical applications but the chemical bonding is sometimes too weak and the labelled molecules are then not stable enough in vivo.

Bromine radionuclides can be an alternative because their bonding in molecules is stronger than that of iodine; furthermore have interesting decay modes for medical applications. [cf. 1-3] The "non-standard" positron emitters ${ }^{75} \mathrm{Br}\left(\mathrm{T}_{1_{1}}=96.7 \mathrm{~min}\right)$ and ${ }^{76} \mathrm{Br}\left(\mathrm{T}_{1_{1 / 2}}=16.2 \mathrm{~h}\right)$ could be used for medical application.

The ${ }^{77} \mathrm{Br}$, decaying by electron capture with a half-life of $57 \mathrm{~h}$, can be used in Auger-therapy with the opportunity to follow the radioactivity distribution in the body using Single Photon Emission Computed Tomography (SPECT). The shorter lived ${ }^{80 m} \mathrm{Br}\left(\mathrm{T}_{1_{1}}=4.4 \mathrm{~h}\right)$, decaying by isomeric transition, can also be used for Auger-therapy while the $B^{-}$- emitter ${ }^{82} \mathrm{Br}\left(\mathrm{T}_{1 / 2}=35.2 \mathrm{~h}\right)$ has potential for therapy.

The labelling of a molecule with radiobromine can be done, in principle, analogous to the labelling with radioiodine, for which many radiotracers are known and established in nuclear medicine for diagnosis and therapy as well (for early reviews cf. [4,5]). Carrier free

$\bar{a}$ e-mail: b.scholten@fz-juelich.de bromine radionuclides can be produced at accelerators and many reaction channels have been examined. Proton and deuteron induced reactions on highly enriched selenium or krypton isotopes offer the production of pure isotopes of nearly any interesting bromine radionuclide with high yield but have the disadvantage of expensive target material and the need of reusable targets.

Indirect production of the lighter bromine isotopes ${ }^{76} \mathrm{Br}$ or ${ }^{77} \mathrm{Br}$ can be done by proton and deuteron irradiations of natural bromine via the product ${ }^{76} \mathrm{Kr}$ and ${ }^{77} \mathrm{Kr}$ which can be separated from the bromine target material, decaying subsequently to the desired radiobromines.

${ }^{3} \mathrm{He}$ particle and alpha particle induced reactions on the monoisotopic arsenic were examined, too, but they are also limited to a few bromine isotopes and furthermore accelerators dedicated to production of medical radioisotopes generally do not offer ${ }^{3} \mathrm{He}$ beams (for early reviews cf. [6,7]). A detailed review of alpha induced reaction cross sections and production of medical radionuclides was recently published be us in Radiochimica Acta [8].

Monoisotopic arsenic as target in radiobromine production has the advantage of low cost, easy target preparation and simple chemical separation without the need of recovering the target material.

Therefore our aim was to re-examine the $\alpha$-particle induced reactions which lead to the bromine isotopes ${ }^{76} \mathrm{Br}$, ${ }^{77} \mathrm{Br}$ and ${ }^{78} \mathrm{Br}$, whose cross-section data are discrepant in literature. All reactions were studied from their respective thresholds up to $37 \mathrm{MeV}$.

\section{Experimental}

\subsection{Targets and irradiations}

Thin arsenic targets, as mandatory for cross-section measurements, were prepared by sedimentation from an 


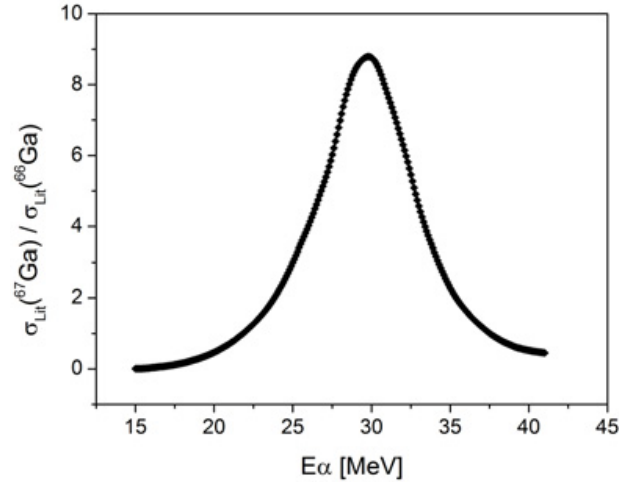

Figure 1. Cross-section ratio of ${ }^{67} \mathrm{Ga} /{ }^{66} \mathrm{Ga}$ of the nuclear monitor reaction $\mathrm{Cu}(\alpha, \mathrm{x})$.

ethanolic slurry on Al backings. The dried sediment was covered by thin $\mathrm{Al}$ foil, and the sandwiches thus obtained, were stacked together with $\mathrm{Al}$ degraders and $\mathrm{Cu}$ monitors, placed in front of each arsenic sample.

The nuclear reactions on $\mathrm{Cu}$ leading to ${ }^{66} \mathrm{Ga}$ and ${ }^{67} \mathrm{Ga}$ served as monitors for the determination of alpha beam flux and energy. The energy degradation within the foil stack was pre-calculated using the code STACK.

The irradiation was performed at the cyclotron CGR560 of the Vrije Universiteit Brussel with $38 \mathrm{MeV}$ $\alpha$-particles in stacked-foil arrangement, using a beam current of about $70 \mathrm{nA}$ for $30 \mathrm{~min}$. Only for crosssection determination of the short-lived ${ }^{78} \mathrm{Br}(6.5 \mathrm{~min})$, the irradiation time was limited to $6 \mathrm{~min}$ in separate experiments. In total 30 irradiations were done.

\subsection{Determination of activity and beam flux}

After activation, the foils within the stacks were separated and the activity of all the Al-As-Al target sandwiches and of the monitor foils was measured $\gamma$-spectrometrically using well calibrated HPGe-detectors. The decay of the radionuclides was followed by recurring measurements.

While during irradiation the beam flux was measured by a Faraday Cup, the exact beam flux was determined by calculation from the monitor reactions on $\mathrm{Cu}$ with ${ }^{66} \mathrm{Ga}$ and ${ }^{67} \mathrm{Ga}$ as the activation products of interest.

Alpha-particles have a much higher stopping power than protons and deuterons and also a stronger straggling. Therefore small errors or uncertainties in the stack preparation as well as increasing energy degradation with decreasing $\alpha$-particle energy within the stack cause higher uncertainties in beam flux calculation.

Therefore we determined reliably the $\alpha$-particle energy in each foil using the cross-section ratio ${ }^{67} \mathrm{Ga}$ to ${ }^{66} \mathrm{Ga}$, shown in Fig. 1, calculated from the evaluated cross sections taken from the IAEA-Website [9].

A comparison of the re-measured $\mathrm{Cu}(\alpha, \mathrm{x})^{66} \mathrm{Ga}$ cross sections, once uncorrected, obtained from the flux detected by the Faraday Cup, and on the other hand corrected, based on the cross-section ratios of the two Ga isotopes, to that of the recommended excitation function from IAEA-TECDOC-1211 [9] showed that only the energy corrected cross sections are in very good agreement with the recommendation. This underlines the necessity of individual energy validation, and its absence in some earlier experiments can explain the deviations in the

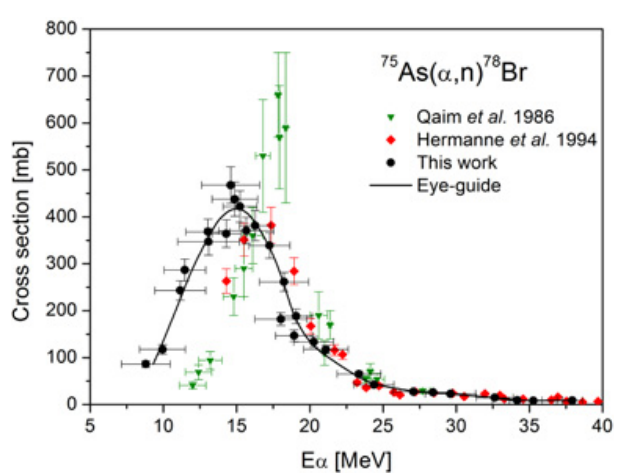

Figure 2. Cross sections of the ${ }^{75} \mathrm{As}(\alpha, \mathrm{n})^{78} \mathrm{Br}$ reaction together with literature data $[10,11]$.

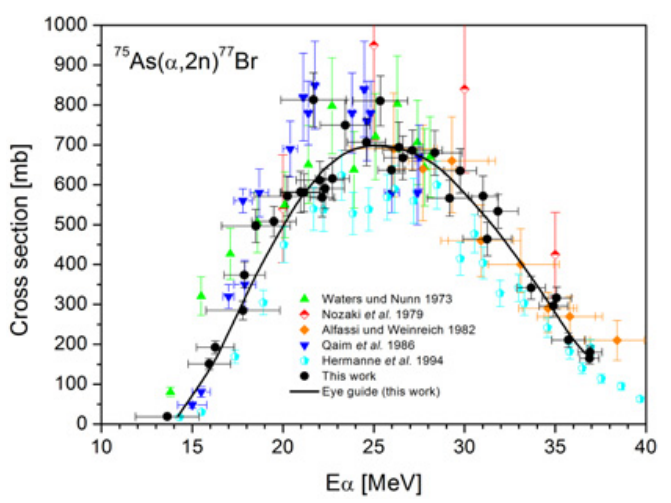

Figure 3. Cross section of the ${ }^{75} \mathrm{As}(\alpha, 2 \mathrm{n})^{77} \mathrm{Br}$ reaction together with literature data [10-14].

literature data of the following nuclear reactions especially when large energy degradations were applied.

\section{Results}

The cross sections given by us are calculated using the above mentioned corrections of the individual beam energy in each As sample and the individual beam flux within a stack based on the monitor foils.

\subsection{Cross section of ${ }^{75} \mathrm{As}(\alpha, \mathrm{n})^{78} \mathrm{Br}$ reaction}

Figure 2 shows our results for the $(\alpha, \mathrm{n})$-reaction on arsenic leading to ${ }^{78} \mathrm{Br}$ in comparison with the data of Qaim [10] and Hermanne [11], which are shifted 2 to $3 \mathrm{MeV}$ to higher energies. The data of Qaim are somewhat higher with a narrower peak at the maximum of the reaction cross sections.

\subsection{Cross section of ${ }^{75} \mathrm{As}(\alpha, 2 n)^{77} \mathrm{Br}$ reaction}

The cross sections of the $(\alpha, 2 \mathrm{n})$-reaction on arsenic leading to ${ }^{77} \mathrm{Br}$ are shown in Fig. 3, together with the literature data [10-14]. Within uncertainties the data are in fair agreement to our data. Nevertheless, small energy shift can be seen and also the values of cross sections differ up to about $30 \%$.

\subsection{Cross section of ${ }^{75} \mathrm{As}(\alpha, 3 n){ }^{76} \mathrm{Br}$ reaction}

Our cross sections of the ${ }^{75} \mathrm{As}(\alpha, 3 \mathrm{n}){ }^{76} \mathrm{Br}$ reaction together with the data of Nozaki, Paans, Alfassi and Hermanne [11,13-15] are given in Fig. 4. The data show energy shifts. The largest shift is in the data published by 


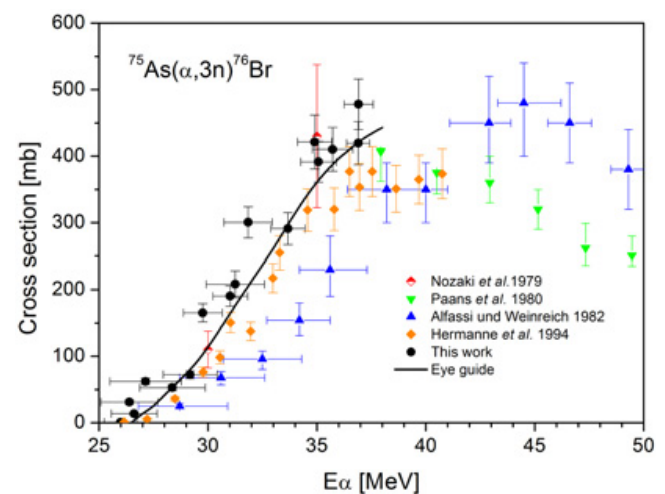

Figure 4. Cross section of the ${ }^{75} \mathrm{As}(\alpha, 3 \mathrm{n}){ }^{76} \mathrm{Br}$ reaction together with literature data [11,13-15].

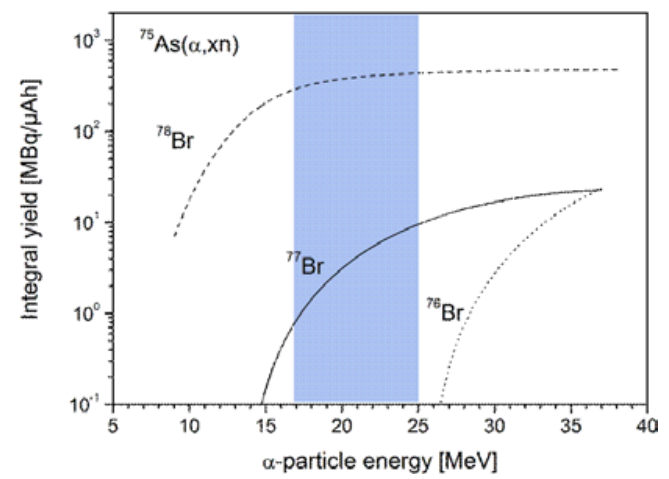

Figure 5. Thick target yields of the ${ }^{75} \mathrm{As}(\alpha, \mathrm{xn})$ reaction products.

Alfassi et al. moved about $6 \mathrm{MeV}$ to higher energies, but their data support our cross-section magnitude. The other data are somewhat lower and slightly shifted also to higher alpha energies.

\subsection{Thick target yields}

Calculating the theoretical thick target yields, given in Fig. 5, on the basis of the respective eye guides, it is obvious that only ${ }^{77} \mathrm{Br}$ can be produced in a quality necessary for medical applications. While ${ }^{78} \mathrm{Br}$ with a half-life of only 6.48 min decays out very fast after the irradiation, the only longer lived bromine isotopes are ${ }^{77} \mathrm{Br}$ $(57.0 \mathrm{~h})$ and ${ }^{76} \mathrm{Br}(16.2 \mathrm{~h})$. Selecting the energy range 25 to $17 \mathrm{MeV},{ }^{77} \mathrm{Br}$ can be produced free of isotopic impurities with a yield of $9.1 \mathrm{MBq} / \mu \mathrm{Ah}$, sufficient for medical application.

The co-produced non-isotopic impurity ${ }^{74}$ As can be chemically separated together with the bulk of arsenic from the radiobromine.

\section{Summary}

We measured the excitation functions of alpha-particle induced reactions on arsenic leading to ${ }^{76,77,78} \mathrm{Br}$. Thereby we used individual corrections of beam energy and flux in each target foil on the basis of the ${ }^{67} \mathrm{Ga}$ to ${ }^{66} \mathrm{Ga}$ crosssection ratios in $\mathrm{Cu}$ monitor foils. This method strengthens the data base and clarifies discrepancies in literature data.

The alpha induced reaction on arsenic is a suitable route to produce ${ }^{77} \mathrm{Br}$ in sufficient amounts and in pure form for medical application.

This reaction will be a promising application at our Cyclone $30 \mathrm{XP}$ accelerator using $30 \mathrm{MeV}$ alpha particle beam to produce ${ }^{77} \mathrm{Br}$ either for medical application or for developing radiolabelling strategies.

The results are related to our $R \& D$ work on the production of radiohalogens.

\section{References}

[1] B. Maziere, C. Loc'h, Appl. Radiat. Isot. 37, 703-713 (1986)

[2] D.J. Rowland, T.J. McCarthy, M.J. Welch, in Handbook of Radiopharmaceuticals, John Wiley \& Sons, Ltd (2003), 441-465

[3] V. Tolmachev, Current Radiopharmaceuticals 4, 76-89 (2011)

[4] H.H. Coenen, S.M. Moerlein, G. Stöcklin, Radiochim. Acta 34, 47-68 (1983)

[5] H.H. Coenen, in: Progress in Radiopharmacy. Development in Nuclear Medicine 10 (Cox PH, Mather SJ, Sambson CB, Lazarus CR, eds.), Martinus Nijhoff Publishers, Dordrecht (1986), 196-220

[6] S.M. Qaim, G. Stöcklin, Radiochim. Acta 34, 25-40 (1983)

[7] S.M. Qaim, Appl. Radiat. Isot. 37, 803-810 (1986)

[8] S.M. Qaim, I. Spahn, B. Scholten, B. Neumaier, Radiochim. Acta 104, 601 (2016)

[9] F. Tárkányi, S. Takács, K. Gul, A. Hermanne, M.G. Mustafa, F.M. Nortier, P. Oblozinsky, S.M. Qaim, B. Scholten, Yu. N. Shubin, Y. Zhuang, Beam monitor reactions: in Charged particle cross section database for medical radioisotope production. IAEA-TECDOC-1211, International Atomic Energy Agency, Vienna 2001, p. 49. www-nds . iaea.org/medical/monitor_reactions.html

[10] S.M. Qaim, G. Blessing, H. Ollig, Radiochim. Acta 39, 57-60 (1986)

[11] A. Hermanne, M. Sonck, J. Van Hoyweghen, D. Terriere, J. Mertens, Proceedings of the International Conference on Nuclear Science and Technology, Gatlinburg, Tennessee, 1039-1041 (1994)

[12] S.L. Waters, A.D. Nunn, M.L. Thakur, J. Inorg. Nucl. Chem. 35, 3413-3416 (1973)

[13] T. Nozaki, M. Iwamoto, Y. Itoh, Appl. Radiat. Isot. 30, 79-83 (1979)

[14] Z.B. Alfassi, R. Weinreich, Radiochim. Acta 30, 67-71 (1982)

[15] A.M.J. Paans, J. Welleweerd, W. Vaalburg, S. Reiffers, M. G. Woldring, Appl. Radiat. Isot. 31, 267-273 (1980) 